Bangladesh J. Sci. Ind. Res. 42(2), 223-228, 2007

\title{
Variation in Lipid Content and Glyceride Compositions of Four Different Varieties of Corn (Zea mays L.) Oil
}

\author{
M. M. Uddin, M. S. Rahman, G.M. Ahmed, M. A. Hossain and A. Samad \\ BCSIR Laboratories, Binodpur Bazar, Rajshahi-6206, Bangladesh.
}

\begin{abstract}
Oil extracted from four different varieties of corn (Zea mays) were evaluated in terms of lipid, glyceride and fatty acid compositions. The total lipid extracts were fractionated into lipid classes by silicic acid chromatography. The neutral lipids were found to be 96.80 - $97.50 \%$; glycolipid 1.50-1.66 \%; phospholipid 0.80-0.95 \% respectively. The fatty acid composition of triglyceride (TG) fraction was analysed by gas liquid chromatography (GLC). The percentage composition of fatty acid were found to be linoleic acid 35.62 to $49.5 \%$, palmitic acid 8.7 to $9.9 \%$, stearic acid 1.9 to 2.3 $\%$, myristic acid 0.9 to $1.6 \%$ and linolenic acid 0 to $2.2 \%$.
\end{abstract}

\section{Introduction}

Corn, a well-known cereal crop grown under the soil and climatic condition of Bangladesh, is extensively used as food and grain for livestock. It serves also as a raw material for several industrial products but most of the people are quite ignorant about its consistency of good quality edible oil. The kernel of corn consists of three main parts, namely hull or bran, embryo or germ and starchy endosperm. Corn contains about 4 to $5 \%$ of oil, $85 \%$ of which is present in the germ (Reiners, 1978). Corn oil is mainly extracted by two different methods as i) from the germ by a special type of corn crushing machine and ii) from whole ground corn by solvent extraction process by using n-hexane. We followed the second method for the extraction of oil in our present study.
The composition of oil varies with the source and depends on factors such as climatic condition, soil texture, maturity of plant and variety (Anonymous, 1976). So the objective of this study is to evaluate the variations in lipid content and glyceride compositions in different corn varieties in Bangladesh.

\section{Materials and Methods}

Four different varieties of ripe mature corn seeds namely- Suvra, Barnali, Mohar and Sadaf were collected from BARI, Joydevpur, Dhaka. The seeds were cleaned thoroughly and sorted manually to remove defective seeds. The cleaned seeds were crushed into small particles (60 mesh) in a grinding machine and dried in the sun for 1-2 days up 
to the moisture level 4-6 \%. The moisture content in the fresh kernel was determined by IUPAC method (Anonymous, 1976-1977).

The oil were extracted separately by solvent extraction method by using n-hexane in a Soxhlet apparatus (Pominski et al. 1970). After filtration the oils were recovered by evaporating the solvent at reduced pressure and the percentage of oil content was calculated. The physico-chemical characteristics of oils were determined by the AOCS methods (Anonymous,1980).

Separation of lipid classes by column chromatography

The total lipid were fractionated into lipid classes of a Silicic acid column. The silicic acid (E. Merck, Darmstadt, Germany, 70-230 mesh) was washed with water and methanol to remove fines and impurities. It was activated at $120^{\circ} \mathrm{C}$ overnight and again for 1 hour immediately before the column was prepared. For each column 25 g silicic acid was washed with $250 \mathrm{ml}$ of chloroform/ methanol (7:1, v/v), $120 \mathrm{ml}$ chloroform/ methanol (15:1, v/v) and $160 \mathrm{ml}$ chloroform. A slurry of $25 \mathrm{~g}$ of silicic acid in chloroform was poured into the column $(2.2 \mathrm{~cm} \mathrm{i.} \mathrm{d).}$ After the column was washed with $100 \mathrm{ml}$ diethyl ether and $325 \mathrm{ml} 4 \%$ diethyl ether in petroleum ether (b.p. $60-70^{\circ} \mathrm{C}$ ), $300 \mathrm{mg}$ total lipids were dissolved in $5 \mathrm{ml}$ eluting solvent and quantitatively transferred to the column.
The solvent systems used to elute the column were similar to those described by Hirsch and Ahrens (Hirsch and Ahrens, 1958). In a typical fractionation, $60 \mathrm{ml}$ of $4 \%$ diethyl ether in petroleum ether eluted the hydrocarbons and sterol esters, $600 \mathrm{ml}$ of the same solvent system removed the triglycerides and an additional $55 \mathrm{ml}$ eluted the FFA (free fatty acids). Sterols were eluted with $350 \mathrm{ml}$ of chloroform and partial glycerides with an additional $350 \mathrm{ml}$ of acetone and $300 \mathrm{ml}$ of methanol respectively. The elution was controlled with a flow rate of $1.5-2.00 \mathrm{ml} / \mathrm{min}$.

The elution of each fraction was monitored by microslide thin layer chromatography (TLC) to ensure uniformity of separation of each lipid class during silicic acid chromatography and the eluted solvents were collected in a weighed flask. The fractions thus obtained were evaporated in a rotary vacuum evaporator and were dried under reduced pressure before being weighed. The purity of the lipid classes was further checked by TLC on $20 \times 20 \mathrm{~cm}^{2}$ plates coated with a layer $(0.5 \mathrm{~mm})$ of silica gel. The lipid classes were identified by $R_{f}$ comparison with standard references. The neutral lipid classes were developed with petroleum ether :diethyl etheracetic acid (90:10: 1) (Mangold, 1961). The weight percentage of each lipid class was based on total lipid recvered, which average to $99.3 \%$ of the total lipid applied. Phospholiped obtained by column chromatography was estimated as total phosphorus content by AOCS official methods (Anonymous, 1980). 


\section{Fatty acid composition of TG fraction}

The fatty acid composition of the triglyceride (TG) fraction of each variety was analysed as their methyl esters, which was prepared by the boron trifluoride methanol method (Morrisson and Smith, 1994). For methyl ester preparation $50 \mathrm{ml}$ of $5 \% \mathrm{NaOH}$ solution was added with $10 \mathrm{~g}$ of oil and was taken in a separating funnel. Then it was shaken vigorously. On standing two layers (aqueous layer and oily layer) were formed. The aqueous layer was acidified with conc. $\mathrm{H}_{2} \mathrm{SO}_{4}$ $\left(\mathrm{P}_{\mathrm{H}}\right.$-2.5). It was then extracted with petroleum ether (40:60). The etherial layer was treated with $\mathrm{MgSO}_{4}$. After filtration the filtrate was evaporated to dryness (FFA). $1 \mathrm{ml}$ of benzoic acid solution was then added with $2 \mathrm{mg}$ of free fatty acid and again evaporated to dryness. $1 \mathrm{ml}$ of boron trifluoride methanol complex was then mixed to the evaporated mass and boiled for 5 minutes in a water bath. It was then extracted with n-Hexane. The volume was reduced preferably by using a rotary vacuum evaporator. The methyl ester thus formed was then used for the fatty acid analysis. The analysis was carried out by a GCD Pye Unicam gas chromatograph equipped with a flame ionization detector. Nitrogen carrier gas was used at a flow rate of $25 \mathrm{ml} / \mathrm{min}$. Fatty acid esters were separated on a $1.8 \mathrm{ra} / 2 \mathrm{~mm}$ i.d glass column packed with $6 \%$ BDS (Butanediol. succenate polyesters) on solid support anakoram ABS 100/120 mesh. Analysis was carried out at isothermal column temperature of $190^{\circ} \mathrm{C}$, injector and detector temperature for all GLC analysis was $200^{\circ} \mathrm{C}$. The peaks were identified by comparison with standard methyl esters for retention times, by plotting the log of retention times against equivalent carbon length (ECL). The peak areas were determined by multiplying peak height by peak width at half height. The percentage of each peak was calculated as the percentage of the total area of all the peaks.

\section{Separation of saturated and unsaturated fatty acid present in corn oil}

Separation of saturated and unsaturated fatty acid was carried out by Lead-Salt ether method on about 50g of oil (Das, 1989). The oil was saponified with alcoholic caustic soda to obtain soap solution. A slight excess of lead acetate solution was added to the soap solution to form lead salt of fatty acids which were then separated. Ether was added to the mixture of lead salt and the whole mixture was boiled and then cooled at $0^{\mathrm{O}} \mathrm{C}$ for 24 hours. The precipitated lead salt of saturated fatty acids so formed were separated from the solution of lead salts of unsaturated fatty acids by filtration. The lead salt of the unsaturated fatty acid were obtained by removing the ether from the ethereal solution. Each group of lead salt was suspended in water and treated with sufficient hydrochloric acid (36 \%) to form fatty acid and lead chlorides. The mixture was then extracted with ether to obtain the ethereal solution of each group. On evaporating the ether, the fatty acid were 
obtained in separated groups. Finally masses of saturated (6.08 g) and unsaturated (43.21 g) fatty acid were obtained by weighing them separately.

\section{Results and Discussion}

Corn kernels from four different varieties have been studied to evaluate the oil content and lipid class compositions. The physicochemical characteristics of the extracted oils of four different varieties of corn kernels were determined by the AOCS (1980) methods and the results are shown in Table I. It was observed that no significant difference of Sp. gravity and refractive index among four varieties was found and which is similar to other good quality edible oils (Hilditch, 1949). Slight variations of Iodine values indicated that the degree of unsaturation decreases with the increase of oil content of different varieties of the corn kernel. Percent of free fatty acid (FFA), saponification values and peroxide values were more or less same among the three different varieties. This result is in good agreement with the reported result of Lofland (Lofland, 1954).
Table II revealed that neutral lipid of all varieties were almost similar. But there was a close similarity between the Suvra (97.50 \%) and Mohar (97.30 \%) varieties and Barnali (96.46 \%) and Sadaf (96.80 \%) varieties regarding their neutral lipid contents. It is remarkable to note that the percentage of phospholipid was found to be $0.95 \%$ in the Suvra variety which is higher than those of other three varieties.

Table II. Weight percentage of lipid compositon of corn

\begin{tabular}{c|c|c|c|c}
\hline Variety & $\begin{array}{c}\text { Total } \\
\text { lipid }\end{array}$ & $\begin{array}{c}\text { Neutral } \\
\text { lipid }\end{array}$ & $\begin{array}{c}\text { Glyco- } \\
\text { lipid (\%) }\end{array}$ & $\begin{array}{c}\text { Phospho- } \\
\text { lipid (\%) }\end{array}$ \\
\hline Suvra & 3.5 & 97.50 & 1.50 & 0.95 \\
Barnali & 4.5 & 96.46 & 1.66 & 0.82 \\
Mohar & 4.0 & 97.30 & 1.55 & 0.84 \\
Sadaf & 3.1 & 96.80 & 1.60 & 0.80 \\
\hline
\end{tabular}

Mean results of three experiments

The fractionation of neutral lipid classes is shown in Table III. The results indicated that no appreciable change in the triglycerides among the four varieties was observed. It is evident that triglycerides in all the varieties were found to be over $90 \%$ of the total

Table I. Physical and chemical characteristics of corn oil extracted from different varieties of dried ground corn

\begin{tabular}{c|c|c|c|c|c|c|c|c}
\hline Variety & $\begin{array}{c}\text { Sp. gravity } \\
\text { at } 20^{\circ} \mathrm{C}\end{array}$ & $\begin{array}{c}\text { Refractive } \\
\text { index at } 15^{\circ} \mathrm{C}\end{array}$ & $\begin{array}{c}\text { FFA } \\
\text { (\%) }\end{array}$ & $\begin{array}{c}\text { Sap. } \\
\text { value }\end{array}$ & $\begin{array}{c}\text { Unsap. } \\
\text { matter (\%) }\end{array}$ & $\begin{array}{c}\text { Iodine } \\
\text { value }\end{array}$ & $\begin{array}{c}\text { Peroxide } \\
\text { value (\%) }\end{array}$ & $\begin{array}{c}\text { Oil cont- } \\
\text { ent (\%) }\end{array}$ \\
\hline Suvra & 0.916 & 1.470 & 1.5 & 75 & 0.9 & 115.5 & 0.5 & 3.5 \\
Barnali & 0.919 & 1.472 & 1.8 & 71 & 0.9 & 105.5 & 0.7 & 4.5 \\
Mohar & 0.914 & 1.471 & 1.2 & 74 & 1.25 & 125.0 & 0.5 & 4.0 \\
Sadaf & 0.921 & 1.471 & 1.6 & 73 & 0.9 & 130.5 & 0.6 & 3.1 \\
\hline
\end{tabular}

Mean results of three experiments 
Table III. Weight percentage of neutral lipid classes in corn kernel

\begin{tabular}{c|c|c|c|c|c}
\hline Variety & $\begin{array}{c}\text { Hydrocarbon and } \\
\text { sterol esters (\%) }\end{array}$ & $\begin{array}{c}\text { Triglycerides } \\
\text { (\%) }\end{array}$ & $\begin{array}{c}\text { Free fatty } \\
\text { acids (\%) }\end{array}$ & $\begin{array}{c}\text { Free sterols } \\
\text { (\%) }\end{array}$ & $\begin{array}{c}\text { Partial glycerines } \\
\text { (\%) }\end{array}$ \\
\hline Suvra & 0.8 & 93.0 & 1.5 & 0.6 & 2.4 \\
Barnali & 0.7 & 91.5 & 1.8 & 0.6 & 2.1 \\
Mohar & 0.8 & 94.1 & 1.2 & 0.5 & 2.0 \\
Sadaf & 0.7 & 92.8 & 1.6 & 0.7 & 2.4 \\
\hline
\end{tabular}

Mean results of three experiments

weight of the lipid. The free fatty acid level was the lowest (1.2\%) and triglyceride was the highest (94.1\%) in Mohar. Hydrocarbon, free sterols and partial glycerides showed no remarkable variation among four varieties.

The saturated and unsaturated fatty acids were separated by Lead salt-ether method (Das, 1989) and the results are depicted in Table IV. It is seen that the lowest percentage of saturated (10.90\%) and the highest percentage of unsaturated fatty acids $(88.10 \%)$ were observed in the oil of Barnali, which is somewhat different from those of other three varieties. From the result shown in Table IV, it is evident that saturated and unsaturated fatty acids in all the four varieties were averaged to 12.5 and $87.5 \%$

Table V. The fatty acid compositions of corn oil (weight \%) by GLC

\begin{tabular}{c|c|c|c|c|c|c}
\hline \multicolumn{7}{c}{ Fatty acids (weight in percent) } \\
\hline Variety & $\mathrm{C}_{14: 0}$ & $\mathrm{C}_{16: 0}$ & $\mathrm{C}_{18: 0}$ & $\mathrm{C}_{18: 1}$ & $\mathrm{C}_{18: 2}$ & $\mathrm{C}_{18: 3}$ \\
\hline Suvra & 1.1 & 2.2 & 9.9 & 38.8 & 47.5 & trace \\
Barnali & 1.4 & 2.1 & 8.7 & 36.9 & 48.7 & 1.2 \\
Mohar & 1.6 & 1.9 & 9.2 & 35.6 & 47.6 & 2.1 \\
Sadaf & 0.9 & 2.3 & 9.1 & 37.4 & 49.5 & trace \\
\hline
\end{tabular}

Mean results of three experiments respectively based on the total fatty acid recovered.

The fatty acid compositions of the oils extracted from four different varieties were determined by GLC and the results are shown in Table V. Gas chromatographic analysis showed that the percentage of saturated and unsaturated fatty acids among the four varieties were slightly different. This variation may be due to soil and climatic condition as well as varieties. It is observed that the unsaturated fatty acids present in corn oil were oleic, linoleic and small amount of linolenic acids. From the result it is noticed that the percentage of linoleic acid in corn oil is averaged to $48.32 \%$. This result more or less agrees with the reported result of

Table IV. Weight percentage of saturated and unsaturated fatty acid in corn oils

\begin{tabular}{c|c|c}
\hline Variety & $\begin{array}{c}\text { Saturated } \\
\text { fatty acid (\%) }\end{array}$ & $\begin{array}{c}\text { Unsaturated } \\
\text { Fatty acid (\%) }\end{array}$ \\
\hline Suvra & 12.46 & 85.40 \\
Barnali & 10.90 & 88.10 \\
Mohar & 12.25 & 86.75 \\
Sadaf & 13.10 & 85.50 \\
\hline
\end{tabular}

Mean results of three experiments 
is higher than those of other fatty acids which Kutumba Rao (Kutumba Rao, 1963). As the percentage of linoleic acid is very high (47 to $49 \%$ ) so corn oil may be considered as a dietary source of polyunsaturated fatty acids and hence it may be extensively used as a good quality edible oil.

\section{Conclusion}

From the fatty acid analysis it has been observed that the percentages of linoleic and linolenic acids are averaged to 48.32 and 1.6 $\%$ respectively. So corn oil may be a good source of polyunsaturated fatty acid containing Omega-6 family of fatty acid which may also be a dietary sources of fats. Now a days people of developed and developing countries are looking for polyunsaturated oil for their better health. As corn oil is rich in linoleic acid (48.32\%), so it is effective in clearing darmatities, lowers the degree of saturation of blood $\beta$-lipoprotein with cholesterol and decreases atherosclerosis (Anonymous, 1965).

\section{Acknowledgement}

The authors express their gratitude to Dr. Shirina Begum, Director(in-charge), BCSIR Laboratories, Rajshahi for providing all research facilities.

\section{References}

Anonymous (1965). Brit. Med. J., I, 1507.

Anonymous (1976-1977). International Union of Pure and Applied Chemistry Standard
Methods for the analysis of oils, fats and derivatives, Pergamon press, Paris., 6th Ed.

Anonymous (1976). The Wealth of India, Vol. XI. 73.

Anonymous (1980). Official and Tentative Methods of the American Oil Chemists Society, I and II, 3rd Ed.

Das, R. K. (1989). Industrial Chemistry, Part-2, Kalyani Publishers, New Delhi, India, 279.

Hilditch, T. P. (1949). The Industrial Chemistry of the Fats and Waxes.3rd Ed. Bailliere Tindall and Cox, London, 80.

Hirsch, J. and Ahren, Jr. E. H. (1958). J. Biol. Chem. 233 : 311.

Kutumba Rao (1963). Food Sci., 12 : 71.

Lofland (1954). J. Am. Oil Chemists. Soc., 31 : 412.

Mangold, H. K. (1961). JAOCS, 38 : 707.

Morrisson, W. R. and Smith, L. M. (1994). J. lipid Res., 5 : 600.

Pominski, J., Pearce, H. M. Jr. and Spadaro, J. J. (1970). Food Techno. 24 : 92.

Reiners, R. A. (1978). Corn oil in product of the corn Refining Industry in Food, Seminar Proc., Corn Refiners Association, Washington, DC., 18.

Received : February 05, 2007;

Accepted : June 13, 2007 